\title{
O CONCEITO EDUCATIVO DE SAÚDE NUM ENTRELACE HISTÓRICO-FILOSÓFICO
}

\author{
Wellington Lins de Souza* \\ Vilde Gomes de Menezes**
}

Resumo: O trato da saúde enquanto objeto de estudo ganhou novos contornos na contemporaneidade. A abertura de novas e o resgate de velhas discussões sobre seu conceito e teleologia despertou nova demanda explicativa e de entendimento. Dentre os componentes dessa demanda está a compreensão da construção sócio-filosófica do conceito de saúde nos diversos contextos históricos da existência humana. Dessa forma, o objetivo desse estudo foi construir um entrelace conceitual não linear desses contextos, buscando contribuir ao entendimento da conceituação da saúde. Para tal, o estudo ancorou-se em pensadores clássicos das ciências humanas e sociais, recortando parte de sua obra para utilização contextual pertinente. $\mathrm{O}$ compilado resultou numa somativa linha do tempo epistemológica, evidenciando o objeto de estudo como um elemento historicamente importante e socialmente mutável, tendo íntima relação com preceitos religiosos, metafísicos e científicos.

Palauras-chave: Saúde; Educação; Filosofia; História; Sociologia

Resumen: El tratamiento de la salud como objeto de estudio ha ganado nuevos contornos en tiempos contemporáneos. La apertura de nuevas y el rescate de viejas discusiones sobre su concepto y teleología suscitaron una nueva demanda explicativa y comprensiva. Entre los componentes de esta demanda se encuentra la comprensión de la construcción sociofilosófica del concepto de salud en los diferentes contextos históricos de la existencia humana. Así, el objetivo de este estudio fue construir un entrelazamiento conceptual no lineal de estos contextos, buscando contribuir a la comprensión de la conceptualización de la salud. Para ello, el estudio se basó en pensadores clásicos de las ciencias humanas y sociales, recortando parte de su trabajo para un uso contextual pertinente. La compilación resultó en un cronograma epistemológico sumatorio, mostrando el objeto de estudio como un elemento históricamente importante y socialmente cambiante, que tiene una íntima relación con los preceptos religiosos, metafísicos y científicos.

Palabras claves: Salud; Educación; Filosofía; Historia; Sociología

Falar em saúde nos tempos atuais é entendê-la como um arcabouço complexo, composto por variáveis que se entrelaçam $e$ que incidem cotidiana e decisivamente na vida do ser humano. Sendo a saúde um conceito primordialmente dependente da

\footnotetext{
* Discente do Programa de Pós-Graduação em Educação da Universidade Federal de Pernambuco. Email: wellington.souza@ufpe.br

" Docente do Programa de Pós-Graduação em Educação da Universidade Federal de Pernambuco. Email: vilde.menezes@ufpe.br
}

compreensão humana sobre seus determinantes sociais e científicos, Czeresnia (2003) destaca a sobreposição temporal de paradigmas epistemológicos - a verdade $e$ as diferentes verdades ${ }^{3}$ - notadamente marcante no estudo da temática. Nesse bojo de conhecimentos, a filosofia é peça importante no estudo da saúde, seja por intermédio de

\footnotetext{
${ }^{3}$ Nesse caso remete-se ao conceito Platônico de "verdade", aquela que deve ser buscada como algo literalmente essencial.
}

SOUZA, Wellington Lins de. O conceito educativo de saúde num entrelace histórico-filosófico. Revista Sul-Americana de Filosofia e Educação. Número 32/33: nov. 2019 - out. 2020, p. 214-220. DOI: https://doi.org/10.26512/resafe.v1i32/33.35124 
filósofos que trataram diretamente a temáti$\mathrm{ca}^{4}$, ou por reflexões, como tratou Martins (2004), advindas de trabalhos tangentes à episteme dos diversos pensamentos em saúde embebidos no positivismo, no materialismo histórico, no estruturalismo, na fenomenologia ou noutra corrente teórica.

Nos tempos atuais, o conceito de saúde é definido pela Organização Mundial de Saúde como um estado de completo bemestar físico, mental e social e não somente a ausências de afecções e enfermidades (SEGRE; FERRAZ, 1997, p. 539). Mas nem sempre foi assim. Os primórdios do entendimento sobre o "estar ou não saudável" traziam a magia, as forças (sobre)naturais e o medo - de cunho religioso - como elementos impositivos ao bem estar corporal. Antes mesmo do surgimento formal da filosofia o ser humano já se deparava com a busca por uma lógica explicativa.

Na Grécia, berço da filosofia, a posição social do indivíduo, a sazonalidade, o trabalho e o ambiente davam a tônica dos componentes sociais (LOURENÇO et al, 2012, p. 19). A filosofia seria, por época, a "medicina da alma". A Idade média trouxe a quebra da lógica grega e a fortificação e consolidação da religiosidade e do teocentrismo como vetores de acesso às condições almejadas como as principais para o ser humano, além do princípio do higienismo físico e do clima de incerteza de métodos e da própria ciência. No Renascimento emergiram as ciências de base e a necessidade das comprovações científicas e do estudo da gênese da matéria e dos agravos ao ser humano. Por fim, na modernidade, o corpo do trabalhador passou a ser determinante para o capita-

\footnotetext{
${ }^{4}$ Canguilhem e Foucault, como notórios expoentes.
}

lismo pungente e o aumento da industrialização e da produção a ele ligada (GUIMARÃES; MENEGHEL, 2003, p. 355). As grandes cidades cresceram geometricamente, trazendo de forma indelével problemas ligados ao saneamento e às questões biológicosociais. Por fim, no século XX, observa-se a emergência da chamada "medicina social", da "saúde coletiva" e das ações de promoção e propagação da saúde, dinamizando a saúde num conceito mais holístico para um sujeito, agora, mais competitivo e individual (GUIMARÃES; MENEGHEL, 2003, p. 357). Nesse sentido, o objetivo deste texto é estabelecer uma reflexão dialética entre a historicidade do conceito de saúde e alguns preceitos filosóficos clássicos, buscando a construção de um entrelace não cronológico, mas hermenêutico. É importante compreender que os filósofos clássicos utilizados nesse texto não direcionaram suas obras diretamente ao estudo da saúde. Nesse sentido, os trechos a seguir tratam de um desafio de entendimento contextual sobre alguns dos mais conceituados paradigmas da filosofia humana e sua relação com o desenrolar histórico do conceito de saúde.

O primeiro conceito formal de saúde encontra base epistemológica na sinergia entre a filosofia e a medicina pré-socrática (AIUB, 2005, p. 114). De uma forma geral, a descoberta do funcionamento do corpo (humos) e da alma - pelo médico e pelo próprio sujeito, respectivamente - era chave para tratamentos e reestabelecimentos. Essa dicotomia corpo e mente difere drasticamente de enunciados onde corpo e mente não se dissociam, possibilidade esta trazida por Freud, Lacan, Espinoza, Nietzsche e Althusser, por exemplo (MARTINS, 2004, p. 950). 
Imbuído da lógica filosófica grega da Aretés, Sócrates buscava conduzir o indivíduo na descoberta dos conhecimentos sobre seu próprio corpo e sobre sua própria alma - a chamada "Maiêutica" socrática. A verdade geral, como sublinham Silva e Pagni (2007) estava latente em todo ser humano.

A filosofia de Aurelius Augustinus, o Santo Agostinho (354-430), configurou-se como grande expoente no trato de saúde à época. "A verdade está em Deus", diferente do modo grego de concepção do conhecimento, onde a verdade estaria no homem. Somente com a permissão $e$ o acesso à linguagem divina (que era interior) o homem poderia compreender de fato o que estava acontecendo com seu corpo. Ao afirmar que o homem é um ser pensante e seu pensamento não se confundiria com a materialidade do seu corpo, Agostinho deixava clara a dicotomia herdada da escola grega sobre o entendimento das mazelas humanas. "Uma alma que serve a um corpo" (OS PENSADORES, 1979, p. 15). Apesar do servir dito por Agostinho, a alma comandaria as ações corporais, sem ser, contudo, modificada por estas. A saúde era obtida pela estabilidade da alma e pela exatidão advinda de Deus e não pela instabilidade do corpo e suas sensações.

A transição para a idade moderna chega com a quebra do conceito religiosocientífico da idade média. O surgimento do estudo da matéria, das ciências de base e de novas tecnologias medicinais, como o microscópio (fundando a base da bacteriologia e da microbiologia) acontece em paralelo com o pensamento positivista e pragmático simbolizado pela chamada "lógica Cartesia-

\footnotetext{
${ }^{5}$ Virtude ou excelência intelectual e moral.
}

na”. René Descartes (meados do século XVII) busca a afirmação de um conceito moderno à época, tornando os sentidos $e$ sensações como catalisadores do autoconhecimento, combatendo a ciência da idade média, esta essencialmente Aristotélica. Assim como Michel de Montaigne (15331592), Descartes (OS PENSADORES, 1973, p. 17) ressaltou a contribuição dos fatores pessoais, sociais e culturais como influenciadores sobre as ideias, buscando o abandono a superstições e fanatismos. O ceticismo sugira com força. $\mathrm{O}$ racionalismo moderno de Descartes, que busca na razão (sobretudo na matemática) os recursos para a recuperação da certeza científica, desencantava das ciências humanas a responsabilidade sobre a atenuação das questões humanas, dentre elas a saúde.

O ceticismo às explicações empíricas sobre os agravos corporais e as dúvidas medicinais sobre as origens $e$ fins de doenças advém dessa lógica. Descartes elencava a "medicina pragmática" como a única natureza de conhecimento eficaz no trato da saúde. Todavia, mesmo divorciando-se dos preceitos aristotélicos, ele ainda concebia a dualidade corpo/mente, mesmo que apresentando explicação mais engenhosa para tal. Deus era a garantia de que "sou uma coisa que pensa" e de que "tenho realmente um corpo" (OS PENSADORES, 1973 p. 25). Em face às novas descobertas e técnicas positivistas surgem vários estudos na anatomia, fisiologia, epidemiologia e a teoria miasmáti$\mathrm{ca}^{6}$ (LOURENÇO et al, 2012, p. 24). A modernidade traz, por fim, base para o desen-

\footnotetext{
${ }^{6}$ Creditava às condições sanitárias a criação de um estado atmosférico responsável por causar doenças infecciosas e surtos epidêmicos.
} 
volvimento teórico das ciências sociais, culminando com o desenvolvimento da medicina social. A origem das doenças passaria, agora, a ser estudada socialmente.

A dinâmica do conhecimento ao longo do tempo e da evolução intelectocientífica constitui uma referência ao que dizia John Locke (1621-1704). "A maneira pela qual adquirimos qualquer conhecimento constitui suficiente prova de que não é inato" (OS PENSADORES, 1999, p. 37). A dicotomia corpo/mente ainda é presente em Locke, que traz o conceito de "experiência social" (ideia). Segundo Locke, somos capazes de juntar conceitos para formar a ideia na mente, sem necessariamente ter vivido a experiência, permitindo, por vezes, um acordo universal entre os homens a cerca de uma verdade. Esse paradigma inclui, por definitivo, o pensamento social nas discussões de saúde, descartando apenas a falseabilidade dedutiva como o caminho a ser seguido. Enunciados singulares deveriam ser observados.

Ainda na mesma época, a obra de Georg Wilhelm Friedrich Hegel (1770-1834), construída também sob um iluminismo propositivo à quebra de determinados estados das coisas, trata a totalidade do real englobando os aspectos sociais, por consequência assim, também a saúde (OS PENSADORES, 1999, p. 28). O entendimento do complexo como preceito para o entendimento das questões do sujeito (NOVELLI, 2001, p. 66). Nesse sentido, entender a saúde como algo complexo e de grande raio de abrangência parece ser uma analogia aceitável nessa perspectiva.

Chama atenção nessa trajetória as axiologias envolvidas nesses paradigmas, paradoxalmente concordando com a lógica defendida por Auguste Comte (1798-1857) para o desenvolvimento da ciência:

Conceitos Teológicos $\longrightarrow$ Metafísicos $\longrightarrow$ Positivistas.

Figura 1. Episteme científica humana (adaptado de COMTE, 1978)

Paradoxalmente porque atualmente o conceito de saúde inclui variáveis essencialmente definidas como de natureza "qualitativa", contrastando com os preceitos "quantitativos", positivistas ${ }^{7}$, emergidos nos estudos sociológicos de Comte, sobretudo acerca da organização coletiva dos sujeitos.

Não obstante, a contemporânea contribuição de David Émile Durkheim (18581917) para os estudos sociais em saúde é potencial. Ao criticar o método universal para todas as áreas, Durkheim apresentou-se bastante importante para a consolidação dos estudos sociológicos gerais, visto que focava seus esforços filosóficos no contexto social circunferencial e não no individual. É de Durkheim o estudo das recorrências sociais que tem poder de se impor ao sujeito, o chamado fato social. Por possuir característica geral (abrangendo o conjunto), por ser algo externo ao indivíduo e ser independe da psicologia do sujeito, a definição da saúde como um fato social pôde garantir, sob a ótica positivista ${ }^{8}$, um raio maior de investigação sobre os agravos, promotores e determinantes relacionados. Atrelado a isso, as sen-

\footnotetext{
7 Seu positivismo fundamentou-se como aquilo que pode ser observado. A disciplina ocasionada pelo método adequado à objetividade buscaria um conceito universal para a saúde.

${ }^{8}$ Nesse caso o contexto histórico não importa. O fato social é algo presente, que requer análise tangível.
} 
sações seriam indispensáveis para o entendimento da saúde como um fato social. Contudo, apenas a contribuição social não parecia ser suficiente para o trato da complexidade do trato de saúde.

O alemão Karl Marx (1818-1883) trouxe uma visão essencialmente política para a filosofia social. A teleologia envolvida nas políticas de saúde voltada à população seria naturalmente direcionada a diferentes abordagens. O cerne da luta de classes e a própria existência das classes sociais da perspectiva Marxista já denotam, por si só, a abordagem fragmentada da saúde à população, podendo incidir numa alienação embebida de falso acesso a serviços e produtos. Assim, a saúde passa pela ideologia à qual a determina, sobretudo em países onde o custeio da saúde pública é estatal. Contudo, para que houvesse na prática, e por conseguinte ${ }^{9}$, a saúde plena, outro paralelo com os preceitos Marxistas pode ser construído: a ausência da necessidade material que a cercasse. Toda e qualquer mudança nas políticas públicas corroboram com a superestrutura analisada nas obras Marxistas.

A Europa à qual ele, Marx, conhecia, levara à inferência de uma saúde holística ideológica, expressando o mundo real (a realidade vivida), mas sem necessariamente ser tangível a uma classe ou a indivíduos a ela pertencentes. Em paralelo, o estudo da força de trabalho e da mais valia configurouse como importante para a sinergia entre corpo e saúde. Logicamente que numa perspectiva de exploração - hegemonia - de uma classe sobre a outra, o trato biológico, socialeconômico e, por conseguinte, da mente,

\footnotetext{
${ }^{9}$ Vale ressaltar que o estudo da saúde direta não era objeto dos escritos Marxistas.
}

constitui grande importância. O chamado "exército industrial de reserva", importante na lógica capitalista, segundo Marx, configuraria, na prática, uma condição estritamente insalubre, uma vez que privaria o indivíduo de acesso a bens materiais básicos, à satisfação mental de estar produzindo e à própria condição financeira básica à subsistência.

Para se entender este e outros fenômenos seria necessário estudá-lo em seu cenário de maior complexidade, porque neste estará a representação mais simples deste fenômeno. Qualquer que seja o fenômeno ele não será uma coisa, mas algo historicamente constituído (OS PENSADORES, 1999, p. 36). Antonio Gramsci (1891-1937) e Louis Althusser (1918-1990), ao também estudarem o aparelho ideológico do estado, trazem evoluções sob o mesmo prisma.

Contemporaneamente, a semiótica $e$ as variáveis sociais apareceram com relevância no trato da saúde, confundindo-se com os próprios determinantes de saúde. Mikhail Bakhtin (1895-1975) trata a consciência como um fato sócio-ideológico, uma vez que só se materializaria através de signos e estes, por sua vez, seriam instaurados em processos de interação social (SILVEIRA, 1981). Sendo assim, é possível que a própria saúde seja um fato sócio-ideológico, não simplesmente um estado biológico normal, buscado pela medicina moderna. Michel Foucault (1926-1984), pesquisador de trato íntimo com as questões de saúde social, afirma que a vida biológica e a saúde das nações tornaram-se alvos fundamentais de um poder sobre a vida, num processo denominado de estatização do biológico. Nesse contexto, mais que nunca, a biopolítica tratada por Foucault emerge questões sócio- 
antropológicas presentes em variáveis de sexualidade, raça e degenerescência, numa nova roupagem de eugenia (ORTEGA, 2004, p.13).

Sendo assim, analisar a construção histórico-filosófica do conceito de saúde torna possível inferir que as influências mística, religiosa, metafísica, científica $e$ social seguiram um caminho de sobreposição e dialética entre si. Os componentes políticos são mais recentes nessa discussão sem, contudo, deixarem de aparecer de forma mais tímida ainda no início do pensamento filosófico. Por fim, as correntes filosóficas mais tradicionais algumas vezes demonstram entrelace, embora isso não compusesse seus objetivos nem estivessem em suas respectivas epistemologias.

\section{Referências}

AIUB, Monica. Filosofia Clínica: o que é isto? Cadernos, v. 11, n. 1, 2005, p. 113-121.

ALTHUSSER, Louis. Ideologia e aparelhos ideológicos do estado. Biblioteca Universal Presença, 1970.

CZERESNIA, Dina. O conceito de saúde e a diferença entre promoção e prevenção. In: CZERESNIA Dina; FREITAS, Carlos Machado (org). Promoção da saúde: conceitos, reflexões, tendências. Rio de Janeiro: Ed Fiocruz, 2003, p. 39-53.

GUIMARÃES, Cristian Fabiano; MENEGHEL, Stela Nazareth. Subjetividade e saúde coletiva: produção de discursos na re-significação do processo saúde-doença no pós-moderno. Revista Mal-estar e Subjetividade, v. III, n. 2, 2003, p. 353-371.

GRAMSCI, Antonio. Os Intelectuais e a Organização da Cultura. Rio de Janeiro: Ed. Civilização Brasileira S/A, $4^{\mathrm{a}} \mathrm{Ed}, 1982$.

LOURENÇO, Luciana de Fátima Leite.; DANCZUK, Rutes de Fátima Terres; PAINAZZER, Daiany; PAULA JÚNIOR, Newton Ferreiar de.; MAIA, Ana Rosete Camargo Rodrigues; SANTOS, Evanguelia Kotzias Atherino dos. A historicidade filosófica do conceito saúde. Revista História da Enfermagem, v. 3, n. 1, 2012, p. 18-35.

MARTINS, André. Filosofia e saúde: métodos genealógico e filosófico conceitual. Cadernos de Saúde Pública, v. 20, n. 4, 2004, p. 950-958.

NOVELLI, Pedro Geraldo. O conceito de educação em Hegel. Interface - Comunicação, saúde e educação, v. 5, n. 9, 2001, p. 65-88.

ORTEGA, Francisco. Biopolíticas da saúde: reflexões a partir de Michel Foucault, Agnes Heller e Hanah Arendt. Interface - comunicação, saúde e educação, v. 8, n. 14, 2004, p. 9-20.

OS PENSADORES: Comte. São Paulo: Editora Nova Cultura Ltda, 1978.

. Descartes. São Paulo: Editora Nova Cultura Ltda, 1973.

. Durkheim. São Paulo: Editora Nova Cultura Ltda, 1978.

. Hegel. São Paulo: Editora Nova Cultura Ltda, 1999. 
. Locke. São Paulo: Editora Nova Cultura Ltda, 1999.

. Marx. São Paulo: Editora Nova Cultura Ltda, 1999.

. Santo Agostinho. São Paulo: Editora Nova Cultura Ltda, 1979.

. Sócrates. São Paulo: Editora Nova Cultura Ltda, 2004.

SEGRE, Marco; FERRAZ, Flávio Carvalho. O conceito de saúde. Revista de Saúde Pública, v. 31, n. 5, 1997, p. 538-542.

SILVA, Divino José da.; PAGNI, Pedro Angelo A educação na filosofia de Sócrates. In: (Org). Introdução à Filosofia da Educação: Temas contemporâneos e História. São Paulo: Avercamp, 2007, $320 \mathrm{p}$.

SILVEIRA, Lauro Frederico Barbosa da. A produção social da linguagem: uma leitura do texto de Mikhail Baktin (V. N. Volochinov), Marxismo e filosofia da linguagem. Trans/Form/Ação, v. 4, 1981, p. 15-39.

Recebido em: 02/09/2020 Aprovado em: 04/11/2020 